TAPROBANICA, ISSN 1800-427X. April, 2013. Vol. 05, No. 01: 6-11, 2 pls. (C) Taprobanica Private Limited, 146, Kendalanda, Homagama, Sri Lanka. www.taprobanica.org

\title{
FIRST DESCRIPTION OF FEMALE Plesiophrictus millardi POCOCK, 1899 (ARANEAE: THERAPHOSIDAE)
}

\footnotetext{
${ }^{1}$ Postgraduate program in ecology \& environment, Indian Institute of Ecology \& Environment, New Delhi, India; E-mail: rajeshvsanap@gmail.com

${ }^{2}$ Postgraduate program in wildlife biology \& conservation, National Centre for Biological Sciences, Tata institute of fundamental research, Bangalore, India; E-mail: snakeszeeshan@ gmail.com
}

\begin{abstract}
The genus Plesiophrictus Pocock (1899) was described when found in Matheran to embody $P$. millardi. This species was described based on a male specimen, but the female remained unknown for more than a century. Recent surveys conducted in the known range of the species resulted in the discovery of the female, which is herein described for the first time.
\end{abstract}

Key words: Arachnida, spiders, tarantula, taxonomy, biodiversity, India

\section{Introduction}

The theraphosid spider genus Plesiophrictus Pocock, 1899 is represented in India by at least 8 species considering the recent revalidation of the genus Heterophrictus and the description of Neoheterophrictus (Guadanucci, 2011; Siliwal et al., 2012). Pocock (1899) established the genus Plesiophrictus to embody Plesiophrictus millardi Pocock, 1899, and later a number of new species were described from India under this genus (Pocock, 1900; Gravely, 1915; Tikader 1977). Recently Siliwal et al. (2007) described a new species from Western Ghats, India. Most species have been described prior to 1950 and hence they lack detailed descriptions of the genitalia, leg morphometry, and natural history as in the case of a recent description by Tikader (1977).

While conducting biodiversity surveys in Aarey Milk Colony (AMC) in Mumbai, Maharashtra in 2010, we collected male and female specimens of a species belonging to the genus Plesiophrictus. Generic identification was achieved with the help of a key provided by Raven (1985), Smith (1987, 1990), and Guadanucci (2011). The spermathecae of the collected female specimens did not match with those depicted by Siliwal et al. (2007). Individual species of the genus Plesiophrictus tend to be distributed in a limited geographic 
area (Smith 1987) and thus based on a literature review, Plesiophrictus millardi was found to be the closest geographically known species, i.e. from Matheran. $P$. millardi was described based on a male specimen from Matheran. Comparison of morphological details of the male Plesiophrictus from AMC with the description provided by Pocock (1899) \& Smith (1987) identified the species as $P$. millardi. To confirm the identification, surveys conducted at the type locality of $P$. millardi, i.e. Matheran, yielded a single male specimen which matched the specimens from AMC. Guadanucci (2011) provided detailed description of the holotype of $P$. millardii which also enabled us to confirm our identification. Based on these fresh specimens of $P$. millardi, we will describe the female for the first time and add notes on the male's natural history and distribution. Smith \& Kirk (2001) and Guadanucci (2011) examined the type specimens of $P$. millardi and a male specimen from the type locality is designated as the topotype. Siliwal et al. (2012) described Neoheterophrictus Siliwal \& Raven 2012 with the description of three new species from the Western Ghats of Karnataka and mentioned that this new genus closely resembles Plesiophrictus and Heterophrictus. Though the new genus differs from Plesiophrictus, its distinction from Heterophrictus has not been satisfactorily justified.

\section{Materials and Methods}

All specimens were deposited at Bombay Natural History Society (BNHS), Mumbai, Maharashtra. All measurements were taken to the nearest $0.1 \mathrm{~mm}$ with a Digital Caliper. Spermathecae were dissected and cleaned in clove oil using needles. Specimens were examined using a Labomed CSM2 stereobinocular microscope. Descriptive style follows the standardized descriptive style provided by Mirza et al. (2011). For SEM images of the tibia of leg I, setae were removed. The illustration of $P$. madaraspatanus was extracted from Gravely (1935).

Abbreviations are as follows: ALE, anterior lateral eye; AME, anterior median eye; d, dorsal; fe, femur; me, metatarsus; MOQ, median ocular quadrate; p, prolateral; pa, patella; PLE, posterior lateral eye; PLS, posterior lateral spinnerets; PME, posterior median eye; PMS, posterior median spinnerets; $\mathbf{r}$, retrolateral; ta, tarsus; ti, tibia; $\mathbf{v}$, ventral; BNHS, Bombay Natural History Society; BMNH, Bombay Natural History Museum; ZSI, Zoological Survey of India.

\section{Family Theraphosidae Thorell 1869 Genus Plesiophrictus Pocock 1899}

Plesiophrictus Pocock 1899: 749, type species Plesiophrictus millardi Pocock 1899, by original designation; 1900: 181; Gravely 1915: 273 (part); Raven 1985: 154; Siliwal et al. 2007: 2853; Guadanucci 2011, Platnick 2012. Ischnocolella Strand 1907: 14, type species Ischnocolella senffti Strand 1907 by monotypy, type considered lost (Raven 1985). Synonimized by Raven 1985:155.

Diagnosis: Representatives of the genus differ from those of Heterophrictus and Neoheterophrictus by the lack of stridulating apparatus or scopula on coxae or chelicerae and by the presence of serrula on the prolateral face of the maxillary lobe. Males can be recognized by the presence of short pyriform spines between the two tibial apophysis branches. Spermathecae stalk with two lobes/ seminal receptacles.

\section{Plesiophrictus millardi Pocock 1899}

(Figs. 1-4)

Pocock, R. I., Diagnosis of some new Indian Arachnida. Journal of the Bombay Natural History Society, 12: 744-753.

Holotype: BMNH unknown, male (14 mm); Matheran, Raighad District, Maharashtra India; Millard; (not examined). The specimen is fragmented (Smith \& Kirk, 2001).

Topotype: BNHS SP-62; male (13.36 mm); Matheran, Raighad District, Maharashtra India; Rajesh Sanap \& Zeeshan Mirza; 19 August 2010.

Other materials examined: BNHS SP-64; female $(14.38 \mathrm{~mm})$; Aarey Milk Colony, Mumbai, Maharashtra - India (19 8' 43.73” N, $72^{\circ} 52$ ' 55.39” E, alt. $103 \mathrm{~m}$ a.s.1.); 28 December 2009 and BNHS SP-65; male (12.2 $\mathrm{mm})$; locality same as above; Rajesh Sanap and Zeeshan Mirza.

\section{Description of male (BNHS SP-62)}

Carapace 6.66 × $5.38 \mathrm{~mm}$; abdomen $6.70 \times 3.86$ $\mathrm{mm}$; chelicerae $3.40 \mathrm{~mm}$; posterior median 
spinneret 0.46 x $0.14 \mathrm{~mm}, 0.58$ apart; posterior lateral spinneret (basal $0.50 \mathrm{~mm}$, middle 0.60, distal $0.96 ; \quad$ midwidths $0.38, \quad 0.40, \quad 0.36$ respectively).

Coloration in life (Fig. 1A): Overall blackish, Carapace covered with a mat of golden hair. Metatarsus of leg I snow white. Sternum and leg coaxe reddish brown; abdomen ventrally paler.

Carapace (Fig. 1B): Fovea straight, transverse Length to width 1.23. Carapace overall black covered with a dense mat of silver hair.

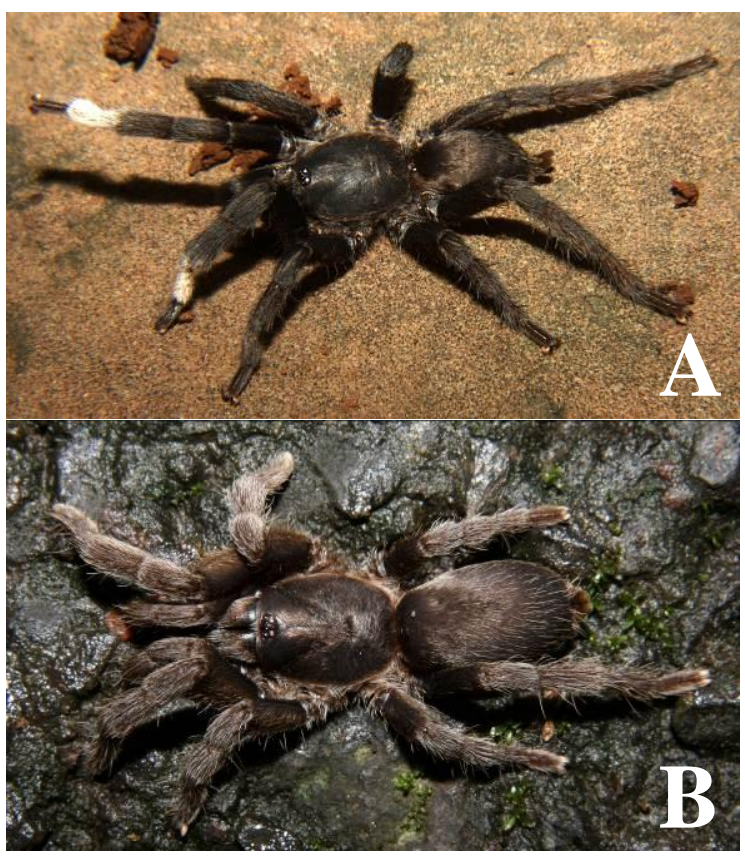

Figure 1: Plesiophrictus millardi, A. male; B. female.

Eyes: Ratio of group width to length 1.5; ALE clearly larger than the rest, PLE slightly larger than AME, and PME clearly smaller than the rest. Eyes on ocular tubercle. Eye diameter: ALE, 0.24; AME, 0.10; PLE, 0.10; PME, 0.08; Distance between the eyes: AME-AME, 0.22; PME-PLE, 0.06; adjacent; AME-ALE, 0.08; PME-PME, 0.30; Ocular Quadrate, 0.52long, 0.78 wide. MOQ: length, 0.18; frontwide, 0.20; backwidth, 0.36; clypeus absent.

Maxillae: Cuspules: ca.45 sparsely arranged anterior corner in triangle region. Posterior edge near heel slightly concave. Maxillary lyra absent.

Labium: 0.48 long, 0.64 wide; ca 12 arranged in tow rows for one-fourth of length anteriorly; the size of labial and maxillary cuspules is the same. Basal groove shallow and distinct. Labiosternal groove convex. One pair of large sternal sigilla present in Labiosternal groove.
Chelicerae: Chelicerae lyra absent. Promarginal teeth 9; 13 basosomal teeth.

Sternum: 2.64 long, 2.04 wide. Oval, high in center, sloping gradually, covered with long, dense, black hair. Posterior angle sharp but not separating coxae IV. Posterior edge clearly seen.

Sigilla: Three pairs; posterior, oval, diameter, ca. $0.08,1.10$ apart, 0.06 from margin; middle, round 0.04 diameter, 1.46 apart, 0.04 form margin; anterior, very small, round, diameter, ca. 0.02, 1.16 apart, marginal.

Legs: (femur, patella, tibia, metatarsus, tarsus, total): I: $4.14,2.64,2.68,2.40,1.50,13.36$. II: $3.44,1.92,2.02,1.72,1.34,10.44$. III: 3.34 , $1.48,1.56,2.02,1.38,9.78$. IV: 4.94, 2.04, 3.02, 3.48, 1.68, 15.16. Palp: 2.94, 1.70, 1.92, , 0.62, 7.18. Midwidths: femora (I, II, III, IV, Palp) 1.40, 1.10, 1.26, 0.86, 0.84; tibia (I, II, III, IV, Palp) 1.10, 0.94, 0.98, 1., 1.14. Formula 4123.

Spines: Tibia II, v1; metatarsus III, d2, p6, r4, v5; Tibia, p4, r3, v6; metatarsus IV, d3, p6, r4+1 broken, v4; Tibia, p3, r4, v8;

Leg coxae: Coaxal bases easily seen from above. Coaxe of Leg I longer than the rest and that of leg III shortest. Coaxe of leg I and II sloping forward and coaxe of leg III and IV sloping backwards.

Scopula: Not very dense as seen in other theraphosids; The tarsal scopulae of leg 1 divided or partly divided, tarsal scopulae leg II divided 2-3 rows of setae, tarsal sclpulae leg III divided 3-4 rows of setae, Tarsal scopulae leg IV divided by 5-6 rows of setae; metatarsus I not divided; metatarsus II 3/4, basal, divided with 2 rows of setae; Metatarsus III 3/4, basal, divided with 2 rows of setae; metatarsus IV $3 / 4$ basal, divided with 3 rows of setae.

Tricobothria: Tarsi I 14-15 calvate and 10-11 long and short filiform in distal half in two rows; Tarsi II 11 calvate and 11-12 long and short filiform in distal half in two rows Tarsi III 18-19 calvate and 14-15 long and short filiform in distal half in two rows Tarsi IV 17 calvate and 13-14 long and short filiform in distal half in two rows; palp tarsi with 10-11 calvate and 9-10 long and short filiform in distal half in two rows.

Tibial apophysis (Figs. 3C-4D): made up of primary and secondary segments. The base of the primary segment bears many small teeth. Secondary segment spine-like and small.

Claws: Paired claws on each leg. Without dentition and single bare claw on palp. 
Spinnerets: Two pairs, with brown hairs. Apical end of PLS, digitiform.

Palp Bulb (Figs. 2E-F): Embolus filiform, broader at base abruptly tapering into a fine point, which curves upwards.

\section{Description of female (BNHS SP-64):}

Carapace 6.26 long, 4.66 wide, chelicerae 6.26 long. Sternum 2.78 long, 2.06 wide. Abdomen 8.12 long, 4.80 wide. Spinnerets (Fig. 4B): PMS 0.52 Long, 0.24 wide, 0.16 apart; PLS length: 0.66 basal, 0.52 middle, 0.62 distal; midwidths $0.54,0.50,0.34$, respectively, 0.76 apart.

Coloration in life (Fig. 1B): Overall in a shade of brownish black. Carapace covered with a dense mat of golden hair. Legs and abdomen covered with blackish brown hair. Sternum and leg coaxe reddish brown; abdomen dorsally covered with mat of brownish black hair but ventrally paler.

Carapace: Fovea straight, transverse. Length to with ration.1.34; Carapace covered with a dense mat of golden hair.

Eyes: Ratio of group width to length.2.27; ALE clearly larger than the rest, PLE slightly larger than AME, and PME clearly smaller than the rest. Eyes on ocular tubercle. Eye diameter: ALE, 0.24; AME, 0.12; PLE, 0.16; PME 0.08. Distance between the eyes: AME-AME, 0.08; PME-PLE, 0.04; AME-ALE, 0.08; PMEPME, 0.42. Ocular Quadrete: 0.44 long, 1.00 wide. MOQ: Length, 0.28 ; front width, 0.28 ; back width, 0.34. Clypeus absent. A few long bristles arise from between the MOQ.

Maxillae: 0.28 long in front and 1.70 in back, 1.02 wide; cuspules ca. 65-70 sparsely arranged in an anterior corner in triangle region. Pro-lateral face with a few scattered short hairs bellow and above the maxillary suture; retro-lateral face smooth and glabrous.

Labium: 0.58 long, 0.90 wide. Ca 13-14 cuspules in band for one-fourth of length anteriorly; cuspules ca. similar in size to maxillary. Basal groove shallow and distinct. Labiosternal groove concave with two distinct sigilla.

Chelicerae: 11 promarginal teeth and 14-15 basosomal teeth; Chelicerae lyre absent.

Sternum: 2.78 long, 2.06 wide; oval, high in center, sloping gradually, reddish, covering with short black hair. Long and short hair radiating from the margin.

Sigilla: Three pairs, posterior oval, 0.16 diameter, ca.1.28 apart, dist. from margin 0.10; middle, oval, 0.08 diameter, ca. 1.92 apart, dist. form margin 0.06; and anterior sigilla marginal. Legs: (femur, patella, tibia, metatarsus, tarsus, total): I: $4.1,2.88,2.88,2.5,1.88,14.24$. II: $3.52,2.26,2.22,1.88,1.62,11.05$. III: 2.98, $1.64,1.72,1.68,1.64,9.66$. IV: 4.90, 2.14, 2.84, 3.04, 2.26, 15.18. Palp: 2.44, 1.66, 1.56, 1.58, 7.24. Midwidths: femora (I, II, III, IV, Palp) 1.76, 1.52, 1.38, 1.12, 1.02; tibia (I, II, III, IV, Palp) 1.12, 1.08, 0.96, 0.98, 0.98. Formula 4123.

Spines: Metatarsus I, v1; metatarsus II, v1; tibia III, p1, 2r, 4v; metatarsus III, 3p, 2r, 3v; tibia IV, 2r, 7v; metatarsus IV, 4p, 2r, 7v;

Leg coxae: Coaxal bases easily seen from above. Coxae of Leg I longer than the rest and that of leg III shortest. Coaxe of leg I and II sloping forward and coaxe of leg III and IV sloping backwards.

Scapulae: Not very dense as seen other theraphosids; tarsi I, entire, divided centrally with 3-4 row of hair, tarsi II, entire, divided centrally with 4-5 row of hair, tarsi III, entire, divided centrally with 6-7 row of hair, tarsi IV, entire, divided centrally with 7-8 row of hair;

Tricobothria: Tarsi I 17-18 calvate and 12-13 long and short filiform in distal half in two rows; Tarsi II 20 calvate and 9-10 long and short filiform in distal half in two rows Tarsi III 15-16 calvate and 11-12 long and short filiform in distal half in two rows Tarsi IV 20 calvate and 13-14 long and short filiform in distal half in two rows; palp tarsi with 15-16 calvate and 9-10 long and short filiform in distal half in two rows.

Claws: Paired claws on each leg. Without dentition and single bare claw on palp.

Spinnerets: Tow pairs, with brown hairs. Apical end of PLS digitiform.

Spermathecae (Fig. 2G): Spermathecae with twin seminal receptacles, each stalk with a short arm arises on the internal aspect resembling a cactus.

Distribution and Natural history: AMC is situated on the southern border of the Sanjay Gandhi National Park - Mumbai (SGNP) and shares a similar mixed moist deciduous type forest, which is more degraded. Specimens of $P$. millardi were found under boulders and rotting logs. The web made by females is messy with multiple entrances, which may lead to a silk lined tunnel. Males were usually found during night trails and on a few occasions under boulders (Fig. 5). Males were found only 
during the monsoons and early winter from June to early November whereas the females were commonly encountered throughout the year except for the monsoons. Juveniles were found in abundance in early November. Specimens were found to be sympatric with Chilobrachyus fimbriatus and Haploclastus validus. P. millardi is common throughout the forested and scrub areas of the SGNP, its surroundings, and Alibaug. Additionally this species has been observed at Matheran, Karnala Bird Sanctuary, Phansad Wildlife Sanctuary, Uran (Raighad District), and Bhimashankar Wildlife Sanctuary (Pune District) in Western Maharashtra (Pocock 1900, Smith 1987, personal observation). The species is distributed in four districts, namely Thane, Mumbai, Pune and Raighad in Western Maharashtra.

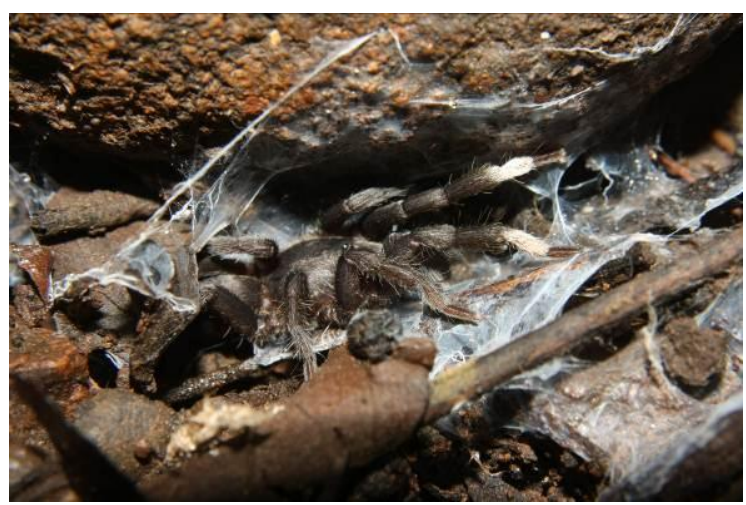

Figure 5: $P$. millardi male from Sanjay Gandhi National Park, Mumbai (not collected).

\section{Discussion}

Males of the genus Plesiophrictus can be identified by the presence of serrula, pyriform setae between the tibial apophysis in addition to the lack of stridulatory structure between chelicerae and maxilla or between coxa of all legs. The pyriform setae are absent in males of the genus Neoheterophrictu. Females possess serrula and the spermathecal stalks bear bilobed/twin receptacles as seen in the type species and $P$. nilagiriensis. Several undescribed species of the same genus also possess similar spermathecase (personal observation) and thus species which lack bilobed/twin seminal receptacles on spermathecal stalks, should be re-examined for correct generic allocation. Images of spermathecae of some Plesiophrictus spp. depicted by Siliwal et al. (2007) appear to possess spermathecal stalks with single or multiple lobes/buds as seen in members of the genus Heterophrictus and Neoheterophrictus, warranting re-examination of those specimens. The proposed character is based on observations from a few species and it is vital to confirm this by examining all material assigned to the genus Plesiophrictus.

Guadanucci (2011) synonymised Plesiophrictus sataraensis Gravely, 1915 after examining the male holotype (BMNH2205/17). Gravely (1915) described $P$. sataraensis based on two males and two females in addition to an immature specimen. The spermathecal structure of the $P$. sataraensis female syntype (ZSI 2207/17) depicted by Siliwal et al. (2007) differs from that of $P$. millardi (Fig. 2G). Thus, fresh collection for the type locality of $P$. sataraensis is needed to ascertain exact status of the species and based on the above mentioned argument we here propose to retain $P$. sataraensis as a valid species until a detailed revision of genus is undertaken. Based on the diagram of the tibial spur of Plesiophrictus madrasspatanus Gravely, 1935 (Fig. 6), we transfer the species to the newly described genus Neoheterophrictus. Guadanucci (2011) examined a female specimen from Satara (Koyna Valley, Helvak, Bombay) 28-30 April 1912 (BMNH 16.5.2.15) with the label P. raja but this specimen is wrongly labelled as the species was described from Kavalai, Cochin forest, Kerala in the southern Western Ghats (Gravely 1915). Likely P. raja Gravely, 1915 also might belong to either the genus Heterophrictus or Neoheterophrictus. Based on the description of Plesiophrictus meghalayaensis Tikader, 1977, we presume that it likely belongs to some other genus and hence we consider it as Plesioprictus incertae sedis warranting re-examination of the type for proper generic allocation. Considering the present flux in the taxonomy of this group, a detailed revision is needed after examination of all relevant material.

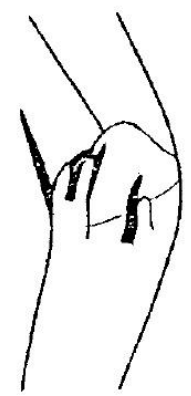

Figure 6: Tibial apophysis of $P$. madaraspatanus after Gravely (1935). 


\section{Acknowledgments}

We would like to thank Vishal Shah, Varun Vaze, Ashish Jadhav and Vishwanath Rathodae for the support in the field and lab work and Rahul Khot for assisting at BNHS. Finally we would like to thank The Gerry Martin Project for logistics, Agarwal Jav Seva Charitable trust for providing equipments and Tata Institute of Fundamental Research (TIFR) - Mumbai for SEM images. Special thanks to the National Centre for Biological Sciences (NCBS, Bangalore) for help with literature and lab facilities. Finally we would like to thank Dimitar Dimitrov (University of Oslo Norway) and Johanna Bleecker (McGill University - Canada) for editing \& reviewing the manuscript.

\section{Literature cited}

Guadanucci, J. P. L., 2011. The genus Plesiophrictus Pocock and revalidation of Heterophrictus Pocock (Araneae: Theraphosidae). Journal of Arachnology, 39: 523-527.

Gravely, F. H., 1915. Notes on Indian mygalomorph Spiders. Records of Indian Museum, Calcutta, 11: 257-287.

Mirza, Z. A., R. V. Sanap and M. Siliwal, 2011. Robust Trapdoor Tarantula Haploclastus validus Pocock, 1899: notes on taxonomy, distribution and natural history (Araneae: Theraphosidae: Thrigmopoeinae). Journal of Threatened Taxa, 3 (10): 2109-2119.

Pocock, R. I., 1899. Diagnosis of some new Indian Arachnida. Journal of the Bombay Natural History Society, 12: 744-753.

Pocock, R. I., 1900. The fauna of British India, including Ceylon and Burma, Arachnida. Taylor and Francis, London: 279.

Raven, R. J., 1985. The spider infraorder Mygalomorphae (Araneae): cladistics and systematics. Bulletin of the American Museum of Natural History, 182 (1): 1-180.

Siliwal, M., S. Molur and R. Raven. 2007. A new species of the genus Plesiophrictus (Araneae: Theraphosidae: Ischnocolinae) from Western Ghats, India. Zoos' Print Journal, 22: 2853-2860.
Siliwal, M., N. Gupta and R. Raven, 2012. A new genus of the family Theraphosidae (Araneae: Mygalomorphae) with description of three new species from the Western Ghats of Karnataka, India. Journal of Threatened Taxa, 4 (14): 3233-3254.

Smith, A. M., 1987. The tarantula: classification and identification guide $\left(2^{\mathrm{nd}}\right.$ edition). Fitzgerald Publishing, London: 178.

Smith, A. M., 1990. Baboon spiders. Tarantulas of Africa and the Middle East. Fitzgerald Publishing, London: 142.

Smith, A. M. and P. Kirk, 2001. A filed Guide on the Threaphosid Spiders of India and Sri Lanka, particularly of the genus Poecilotheria: 26.

Strand, E., 1907. Aviculariidae und Atypidae des Kgl. Naturalienkabinetts in Stuttgart. Jahreshefte des Vereins für vaterländische Naturkunde in Wurttemberg, 63: 1-100.

Tikader, B. K., 1977. Studies on some mygalomorph spiders of the families Ctenizidae and Theraphosidae from India. Journal of the Bombay Natural History Society, 74: 306-319. 


\section{PLATE 1}
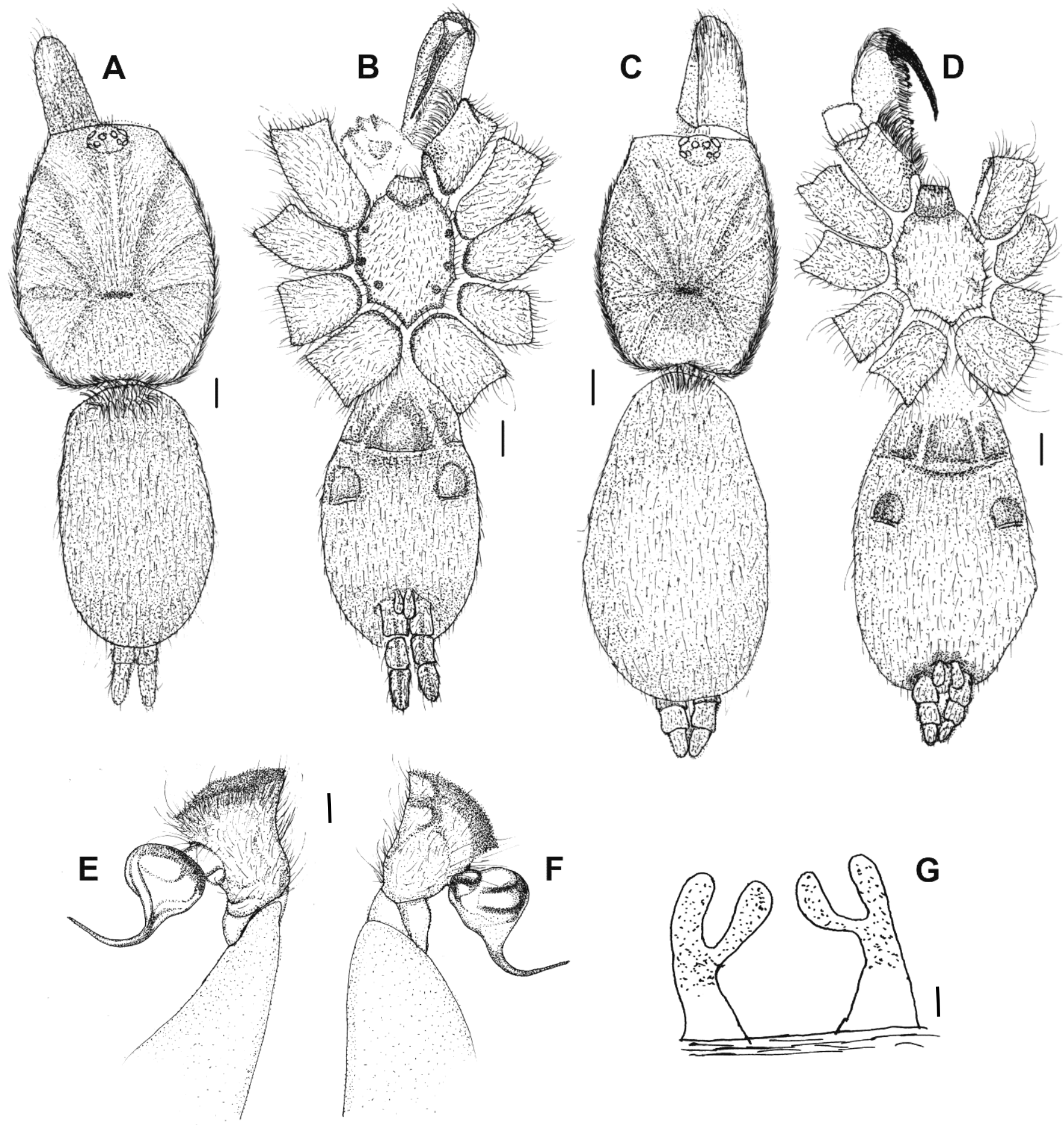

Figure 2: Plesiophrictus millardi A, male dorsal; B, male ventral view; $\mathbf{C}$, female dorsal view; $\mathbf{D}$, female ventral view; E, male palp bulb retrolateral view; F, male palp bulb prolateral view; G, spermathecae (scale: A-D $1.0 \mathrm{~mm}$; E-F $0.2 \mathrm{~mm}$; G 0.1 $\mathrm{mm})$. 


\section{PLATE 2}
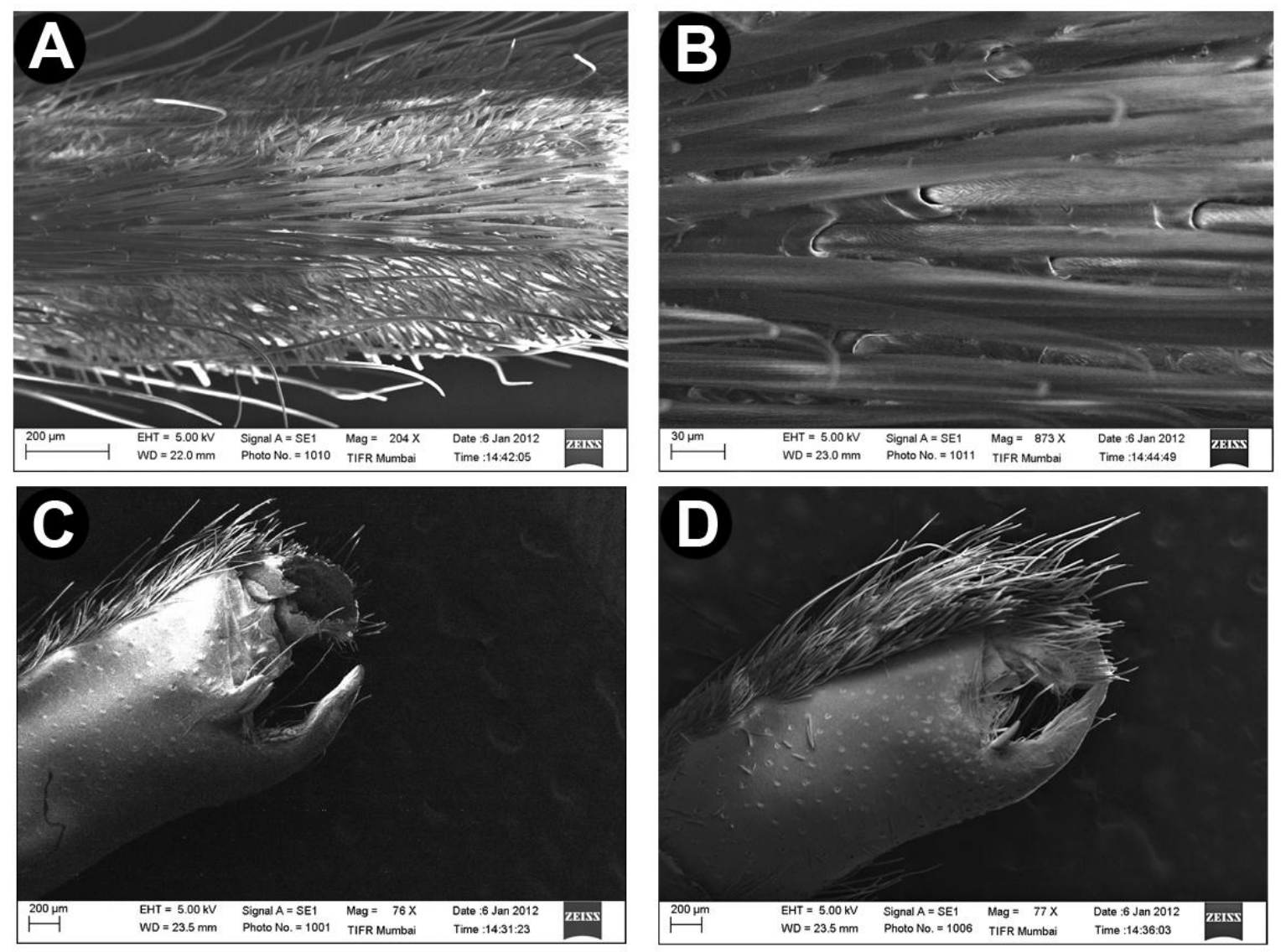

Figure 3: SEM images of Plesiophrictus millardi. A \& B, scapulae division of leg IV by thick setae; $\mathbf{C}$, tibial apophysis prolateral view; $\mathbf{D}$, tibial apophysis retrolateral view.
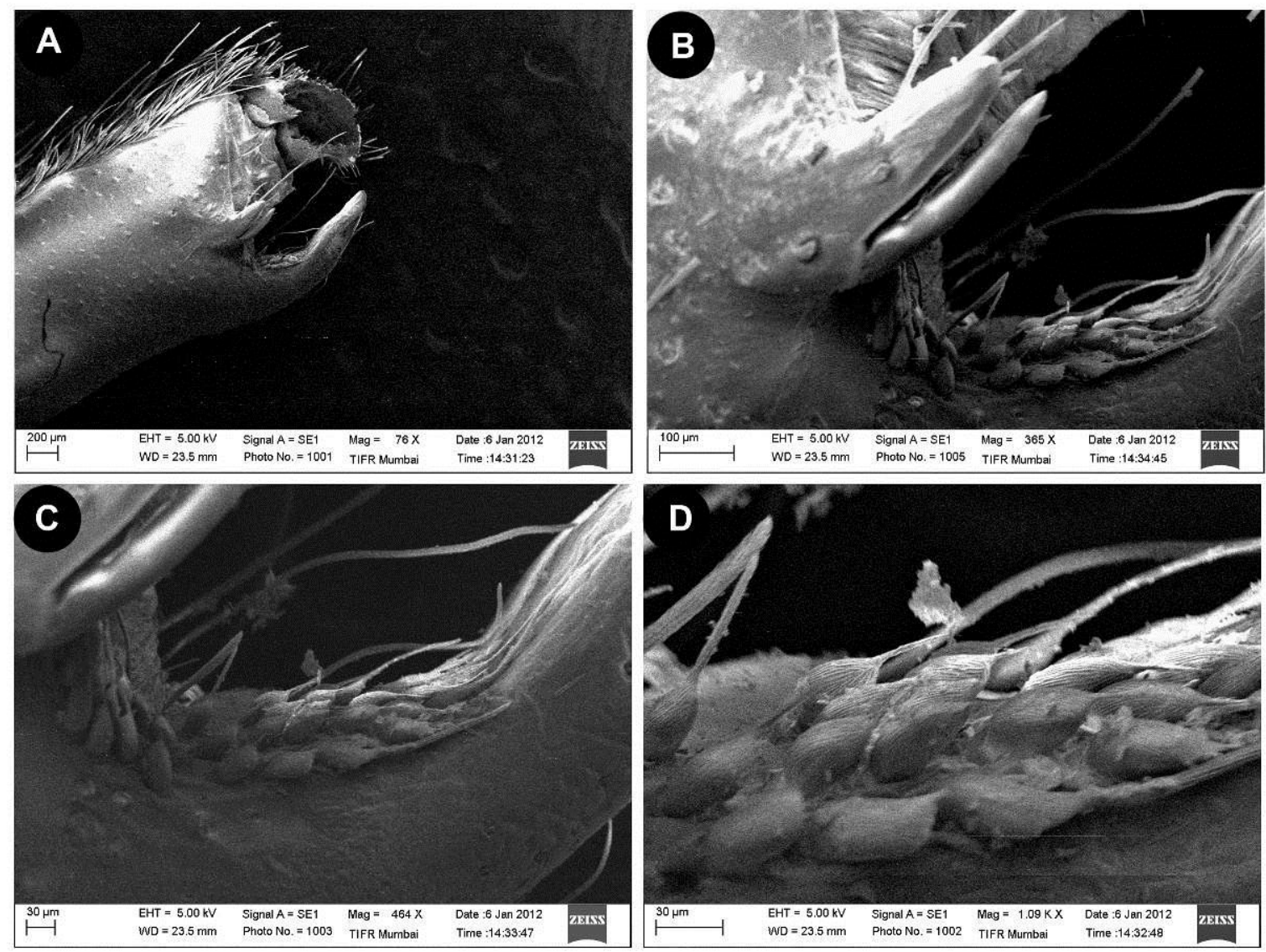

Figure 4: A-D, Tibial apophysis of male P. millardi showing pyriforrm setae between two spurs. 